\title{
Users' satisfaction with the public dental service: the discovery of new patterns
}

\author{
Satisfação de usuários com o serviço público \\ odontológico: a descoberta de novos padrões
}

\author{
Cristina Berger Fadel ${ }^{1}$ (D), Danielle Bordin ${ }^{1}$ (D), Celso Bilynkievycz dos Santos ${ }^{1,2}$, \\ Deborah Ribeiro Carvalho ${ }^{3}$, Suzely Adas Saliba Moimaz ${ }^{4}$
}

\begin{abstract}
Background: Regarding to oral health, little has been advanced on how to improve quality within dental care. Objective: The aim of this study was to identify the demographic factors affecting the satisfaction of users of the dental public service having the value of a strategic and high consistency methodology. Method: The Data Mining was used to a secondary database, contemplating 91 features, segmental in 9 demographic factors, 17 facets, and 5 dominions. Descriptive statistics were extracted to a demographic data and the satisfaction of the users by facets and dominions, being discovered as from Decision Trees and Association Rules. Results: the analysis of the results showed the relation between the demographic factor 'professional occupation' and satisfaction, in all of the dominions. The occupations of general assistant and home assistant with daily wage stood out in Association Rules to represent the lower level of satisfaction compared to the facets that were worse evaluated. Also, the factor 'health unit's name' showed relation with most of the investigated dominions. The difference between health units was even more evident through the Association Rule. Conclusion: The Data Mining allowed to identify complementary relations to the user's perception about the public oral health services quality, constituting a safe tool to support the management of Brazilian public health and the basis of future plans. Keywords: evaluation of the health service; satisfaction; dental care; data mining.
\end{abstract}

\footnotetext{
Resumo

Introdução: Em relação à saúde bucal, pouco se avançou sobre como melhorar a qualidade no atendimento odontológico. Objetivo: $\mathrm{O}$ objetivo deste estudo foi identificar fatores demográficos que afetam a satisfação de usuários do serviço público odontológico, sob a análise de uma metodologia estratégica e de alta consistência. Método: Aplicou-se a Mineração de Dados sobre um banco de informações secundárias, contemplando 91 características, as quais foram segmentadas em 9 fatores demográficos, 17 facetas e 5 domínios. Estatísticas descritivas foram extraídas dos dados demográficos e a satisfação dos usuários foi exposta por meio de facetas e domínios, sendo apresentados a partir de Árvores de Decisão e Regras de Associação. Resultados: A análise dos resultados mostra relação entre o fator demográfico 'ocupação profissional' e a satisfação do usuário, em todos os domínios. As ocupações de assistente geral e empregado doméstico com salário diário destacaram-se nas Regras de Associação para representar o menor nível de satisfação em relação às facetas que foram mais mal avaliadas. De forma complementar, o fator 'nome da unidade de saúde' expôs relação com a maioria dos domínios investigados. A diferença entre as unidades de saúde mostrou-se ainda mais evidente por meio da Regra de Associação. Conclusão: A Mineração de Dados permitiu identificar relações complementares à percepção do usuário sobre a qualidade dos serviços públicos de saúde bucal, constituindo-se em ferramenta segura para subsidiar a gestão da saúde pública brasileira e a base de planos futuros.

Palavras-chave: avaliação do serviço de saúde; satisfação; odontologia; mineração de dados.

IUniversidade Estadual de Ponta Grossa (UEPG) - Ponta Grossa (PR), Brasil.

2Universidade Tecnológica Federal do Paraná (UTFPR) - Ponta Grossa (PR), Brasil.

${ }^{3}$ Pontifícia Universidade Católica (PUCPR) - Curitiba (PR), Brasil.

${ }^{4}$ Universidade Estadual de São Paulo (UNESP) - Araçatuba (SP), Brasil.

Study carried out at Universidade Estadual de Ponta Grossa (UEPG) - Ponta Grossa (PR), Brasil.

Correspondence: Cristina Berger Fadel - Departamento de Odontologia, Universidade Estadual de Ponta Grossa (UEPG), Av. Gal. Carlos Cavalcanti, 4748 Uvaranas - CEP: 84030-900 - Ponta Grossa (PR), Brasil - Email: cbfadel@gmail.com

Financial support: none.

Conflict of interests: nothing to declare.
} 


\section{INTRODUCTION}

In recent years, discussions on the quality of health care is constantly expanding on organizations agenda worldwide, driven by factors such as reduction of adverse events, and efficiency and increasing of users satisfaction with the service ${ }^{1}$. In fact, quality health care is considered a key component in most countries, regardless of level of economic development and health system model adopted ${ }^{2}$, however with no unified operational deliberation.

Several authors have conducted their research on the evaluation of user satisfaction with the public health services, which plays an important role for the consolidation and improvement of public health policies. Particularly, the understanding of the user's satisfaction is exposed as an information provider factor on the everyday problems of health services, providing progress under the production, management and evaluation of action $\mathrm{s}^{3-6}$, leading to a better service delivery in terms of distribution, complexity and quality.

The literature is still unclear and inconclusive regarding the factors that really affect the user satisfaction of the health service. The relationships commonly found refer to socioeconomic condition $^{7}$, level of education ${ }^{8-11}$, age ${ }^{3,8,12,13}$ marital status and gender ${ }^{8}$. However, given the diversity and low power of associating the methods used for crossing the factors of interest, the information obtained become unclear for assertive decision-making.

In relation to oral health, little has been advanced on how to improve quality within dental care. The studies carried out exposed mostly a reductionist approach, restricted to the aspect of the aspect of cost-cutting ${ }^{5}$, reduction of quality and impact on living condition of the health service. When referring to satisfaction with dental care in Brazil, it is pertinent to understand its particularities, such as the extensive territorial area, the public investments deficit in health, social inequalities, lack of professionals, among others, aspects that reflect the availability, access, quality and services solvability, with repercussions on user satisfaction. It is known that considering the users' perspective constitutes a constant possibility for adequacy of health services ${ }^{10,13,14}$. In this sense, there is a need to promote the use of broad assessment methodologies, appropriate to large sets of data, which are capable of not only consider the pluralism of social groups involved, but also ensure the interaction of the user's perspective, supporting decisionmaking and (re)shaping of health practices ${ }^{15}$.

The Knowledge Discovery in Database (KDD) process allows you to identify implicit patterns, which may be potentially useful. In the context of dental users' satisfaction, it can help prioritize their actions.

For these considerations and for the science that the above object must be increasingly present in the health manager's agenda, the aim of this study was to identify demographic, individual and local factors affecting the satisfaction of users with the Brazilian public dental service.

\section{METHOD}

This study is exploratory in relation to its objective and experimental in accordance with its procedures. The data were tabulated and analyzed from a source of data from a cross-sectional, multicentric study, developed in 2014, in the urban area of two medium-sized municipalities, one from state of Paraná and another one from state of São Paulo. The study was approved by the Ethics Committee for Research with human beings of the Sao Paulo State University - UNESP (No353.893/2013).

\section{Context that preceded the study in question}

The study population consisted of dental service users in Primary Health Care scope, distributed in the regular health units on the urban area in the investigated cities.

A sample calculation was performed by Epi.Info software 7.1.4, considering the estimated adult population in the investigated cities, with an accuracy of 5\%, a 95\% confidence interval and a drawing effect 1 . For a prevalence of $50 \%$ of adults satisfied with the quality of dental services. This prevalence was used in order to obtain the largest possible sample. The calculated total (384) was increased by $20 \%$ in order to boost the results, resulting in 461 adults for each municipality, totaling the final sample of the study 922 users.

Inclusion criteria were: to be a user of the dental service of the Unified Health System in the scope of primary health care; have received dental care for a maximum of one year from the interview; be 18 years of age or over; or accompanying minors in a dental appointment on the day of the interview.

The instrument for gathering information was based on tools, proposed by the Brazilian Ministry of Health, that evaluates generally the quality of the public health services, adapted to specific aspects of the dental reality. In order to ensure the understanding of the instrument regarding the text, the vocabulary used and the sensitivity of the answers, a pilot study and quantification of the internal consistency between the questions was carried out using Cronbach's $\alpha(\alpha=0.70)$.

The data collection was performed through an individualized interview, by trained researchers, in a reserved environment, in the health units.

The study was approved by the Ethics Committee for Research with Human Beings of the Sao Paulo State University UNESP ( $N^{\circ} 353.893 / 2013$ ), respecting the principles of Resolution $466 / 12$ of the Brazilian Health Council.

The database consisted of attributes (86) and records (922), distributed in demographic attributes (9) evaluation instrument of satisfaction (55), results of the facets (17) and domains (5). The factors 'age', 'gender,' 'marital status,' 'education', 'income', 'occupation', 'city', 'model of organization of health care' (UBS Basic Unit Health and USF Family Health Unit) and 'intrinsic characteristics of each health unit' (graphically represented 
by alphabetic codes), were part of the demographic attributes. The satisfaction data contemplated facets: 'Distance'; 'Office Hours'; 'Time to schedule the query'; 'Appointments form'; 'Waiting time'; 'Cleaning'; 'Comfort'; 'Signaling'; 'Ability to answer questions'; 'Prevention'; 'Knowledge about specialized care'; 'Attendance'; 'Resolvability'; 'Reception'; 'Education, interest and responsibility'; 'Confidence'; 'Communication returning from specialists appointments'; and the domains: 'Organization of services' (D1); 'Physical structure' (D2); 'Information and Support' (D3); 'Medical Care' (D4); 'Relationship and Communication' (D5). The domains were created from the variables grouping according to the proximity to the basic dimensions of public health services evaluation in Brazil, namely: Medical Care, Information and Support, Organization of Services and Physical Structure, which were shown in consonant with the groupings adopted in equivalent studies ${ }^{3,11,16}$.

\section{Own context of the study in question}

To identify the relationship between demographic factors and the satisfaction of the user on public health service, all stages of the KDD process were adopted, as follows (Figure 1): Pre Processing, Data Mining and Post Processing ${ }^{13,14}$.

In Pre-Processing, descriptive statistics were extracted on demographic data and user satisfaction by facets and domains. From the satisfaction ratings (SR) of facets, averages were composed, relating to the areas that were categorized according to the following ranges: low $(\mathrm{SR} \leq 0.33)$, medium $(\mathrm{SR} 0.33 \leq 0.66)$ and high $(\mathrm{SR}>0.66)$.

The resamping algorithm was adopted to avoid the imbalance between the created categories, which may hinder the discovery of patterns. This strategy has the ability to balance the classes of the dependent variable, favoring the analysis process. From the tests performed with the balancing algorithms available in the WEKA (Waikato Environment for Knowledge Analysis) software, the Resample algorithm presents the best results.

For Data Mining, two forms of representation of the standards were adopted: Decision Trees (DT) and Association Rules (AR). For the DT discovery, we adopted the J48 algorithm and the AR discovery, the Apriori algorithm. Both algorithms are available on WEKA.

The patterns discovered by the data mining show among all the independent variables available those that are more strongly related to the dependent variable, which present greater precision and accuracy ${ }^{17}$.

In this way, it does not only consider the utility of variables individually, but also the level of relationship between them, thereby eliminating any situation of confusion. The variables with non-existent, weak and or redundant relations, which do not bring information gain to the model, are eliminated automatically by the algorithm.

The models discovered from this methodology are more reliable and understandable, making it possible to aggregate

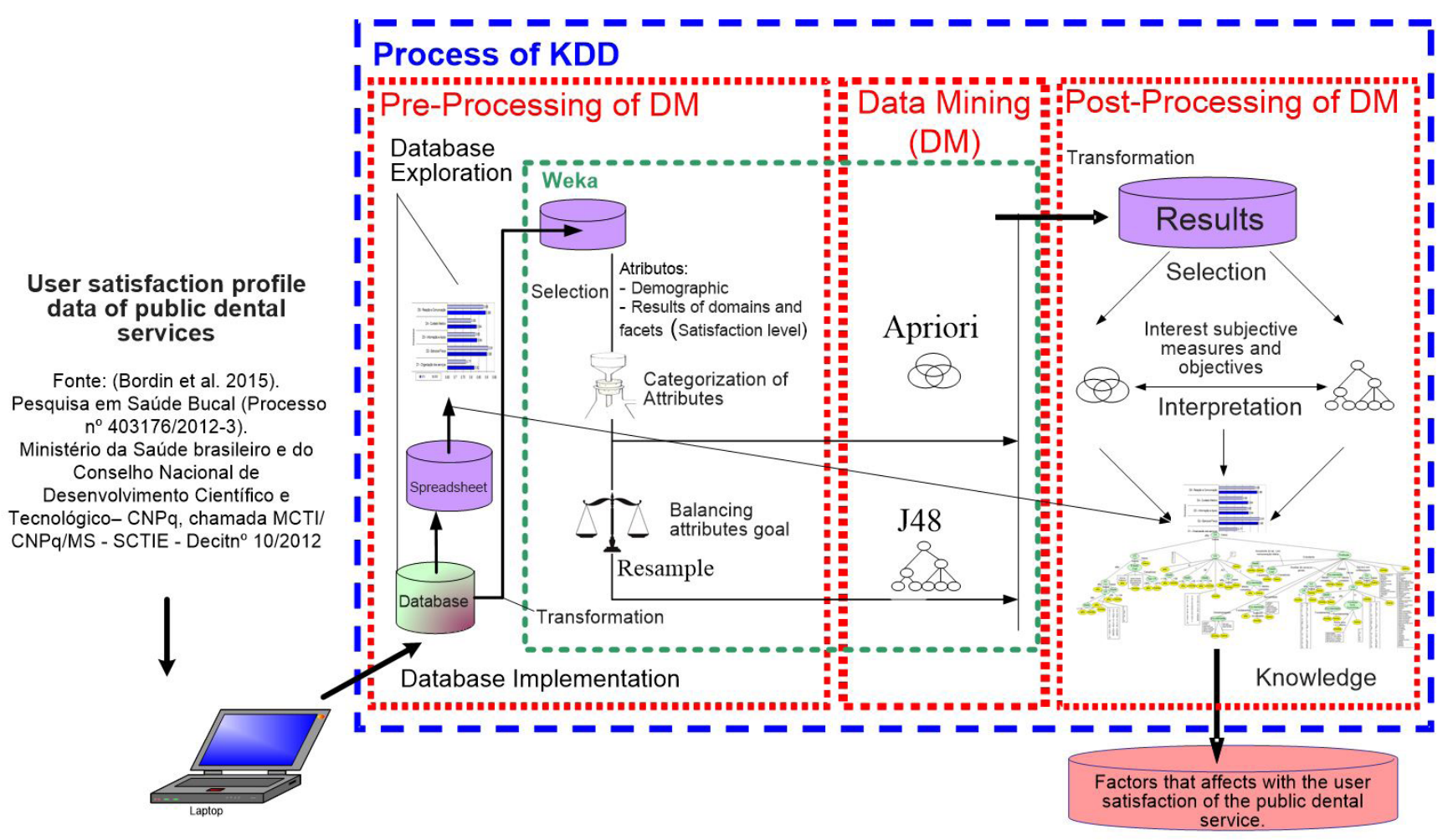

Figure 1. Stages of Research Development, 2014 
potentially useful knowledge from less explored situations, especially considering large data sets such as the present study ${ }^{17}$.

Ten DT were discovered, each related to a domain classification in three satisfaction classes (low, medium, high). To evaluate the predictive accuracy, cross validation was adopted.

Among all the ARs, the associations most strongly related with the variables, identified from the AD ('occupation' and 'intrinsic characteristics of each health unit) were selected, as well as the facets with the lowest degree of satisfaction ('time to schedule the query' and 'capability of all dental health problems resolvability'), observed during the exploration phase of the database.

As an objective measure, the AR with positive dependence were evaluated through Lift measure in data mining $(\mathrm{L})<1$, with a degree of involvement of the antecedent in the consequent by conviction $(\mathrm{Cv})>1.1$, thus avoiding the selection of ARs with casual competition between elements without dependency relationship.

\section{RESULTS}

The results of the KDD data exploration step (Table 1) indicated the participation of 642 members of USF and 280 of UBS, average age of 39 years, single mostly, $80 \%$ women and
$20 \%$ men. Regarding the 'level of education', the predominant categories completed primary education (42\%) and completed high school (35\%). The 'income' users were concentrated between 1 and 2 Brazilian minimum wages (\$246.00). As for the 'occupation', 136 different occupations were identified, being the most frequent (25\%) home (housewife), followed by retired declared individuals (7.0\%).

From Figure 2 it was possible to analyze the evaluation of users by facets and domains. The facet 'time to schedule a dental appointment at the health unit' $(\mu=0.69 \pm 0.42)$ had the lowest average satisfaction rating, followed by the facet 'resolvability' $(\mu=0.76 \pm 0.39)$.

Table 2 presents the predictive quality measures of ten $\mathrm{AD}$ models developed during the experiment.

Figure 3 shows a tree decision model, aiming domain 'Relationship and Communication'. The quality measures of this model of $\mathrm{AD}$ are presented in Table 3, where high precision indexes are observed from the results of Measure F and ROC Area, indicators used to evaluate the hit rates of a classifier, for each attribute. It is also observed that, for the degree of satisfaction 'low' in the domain 'relation and communication', the percentage of hits reached $83.85 \%$, while for the average degree of satisfaction the percentage was $100 \%$ and, for the high

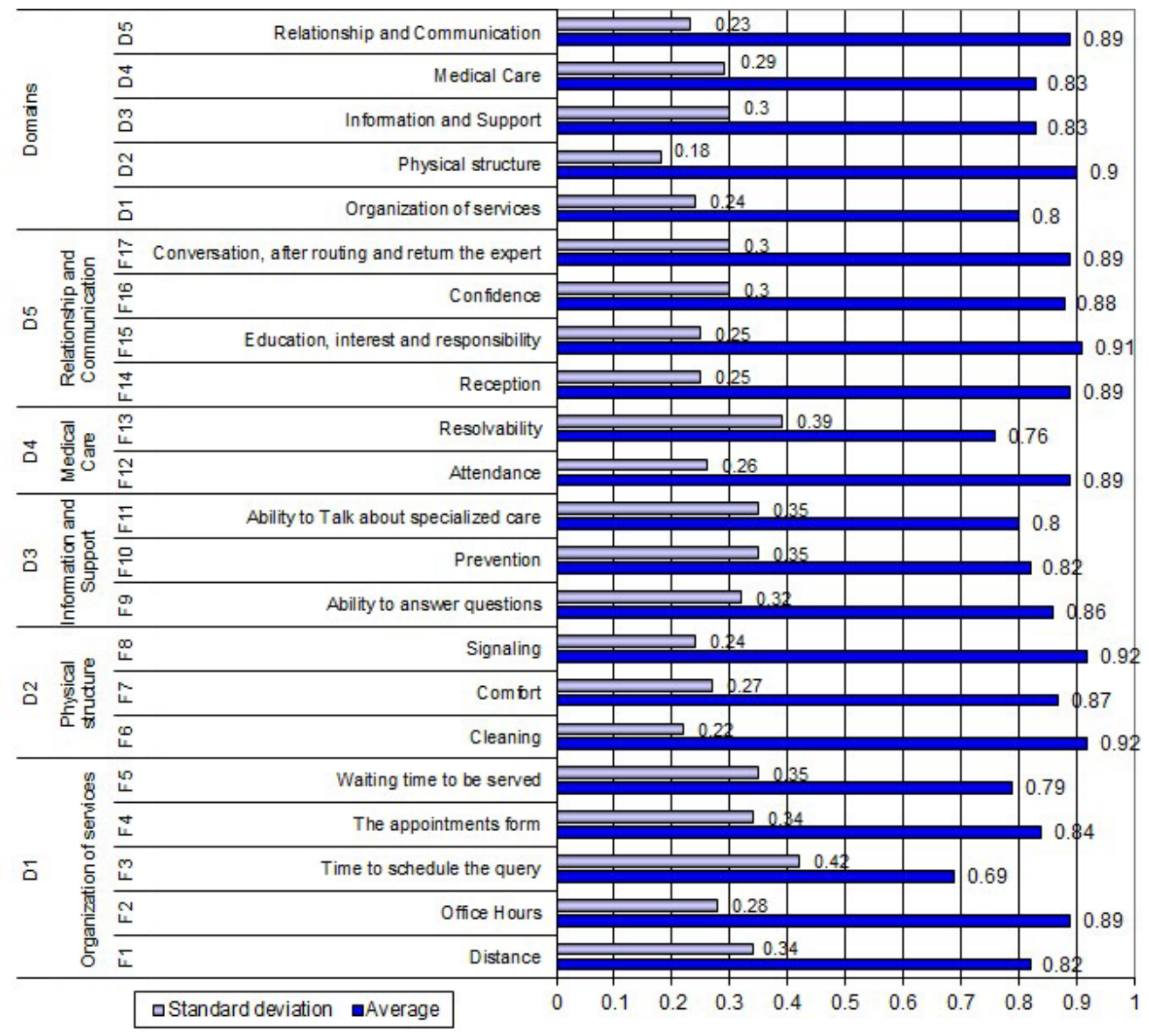

Figure 2. Mean and standard deviation of the satisfaction indexes of users in relation to Domains and Facets that evaluate dental care, 2014 
degree of satisfaction the percentage was $93.31 \%$. The correct classification of the group reached $93.05 \%$.

Still, it was possible to perceive the relationship between the other factors (municipality, model of organization of health care, age, gender, marital status, level of education and socioeconomic status) and satisfaction dominions, but in branches not as close to the root node and lesser degree of relevance.

From Tables 4 and 5 it was possible to identify the AR in relation to 'time to schedule the dental appointment in the US' and 'resolvability', respectively.

Table 1. Frequency (F) and distribution (\%) of demographic variables by class, 2014

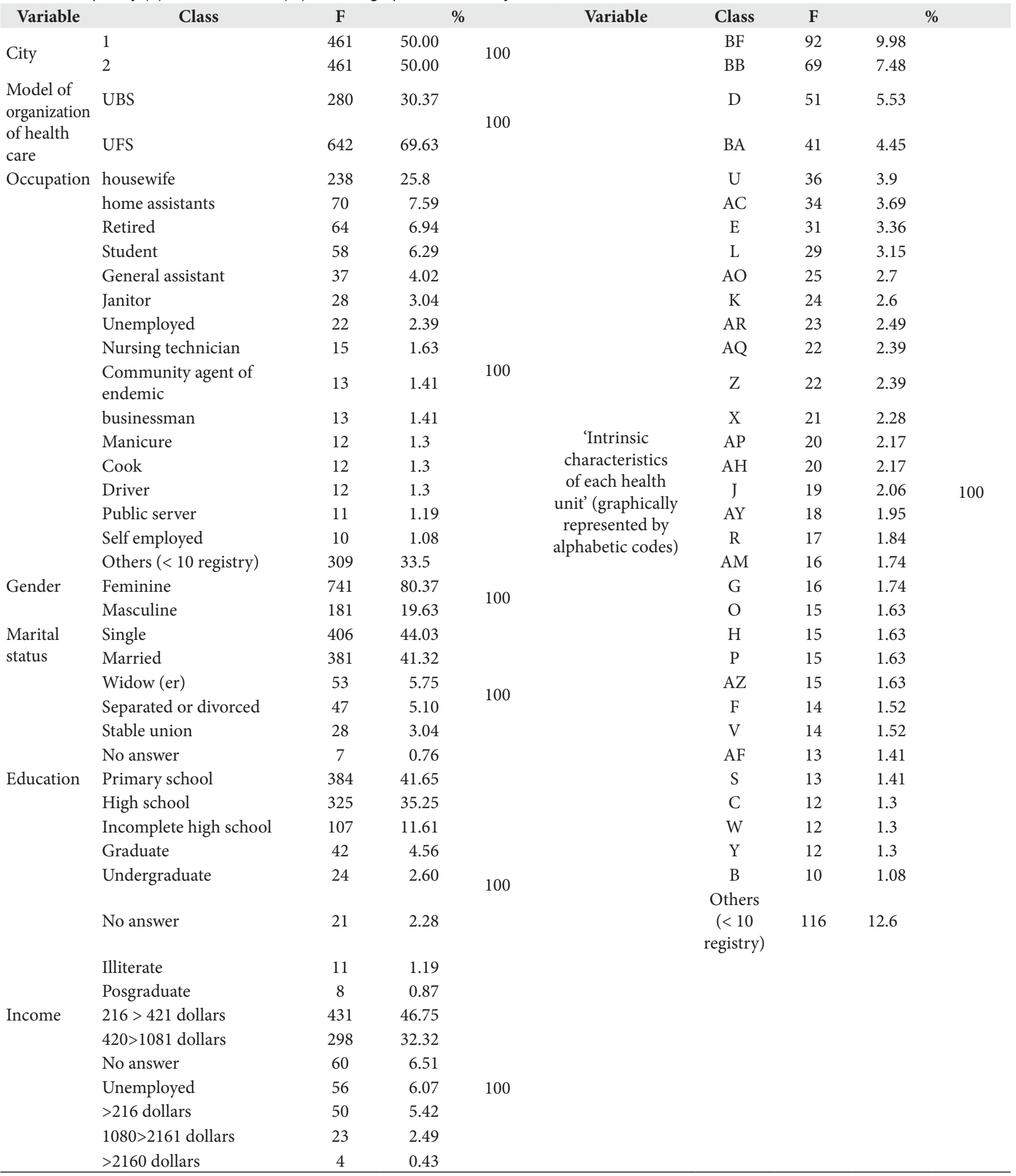


Table 2. Result of the decision tree models generated by the $\mathrm{J48}$ algorithm for each meta attribute set of prediction data and type of training and test, 2014

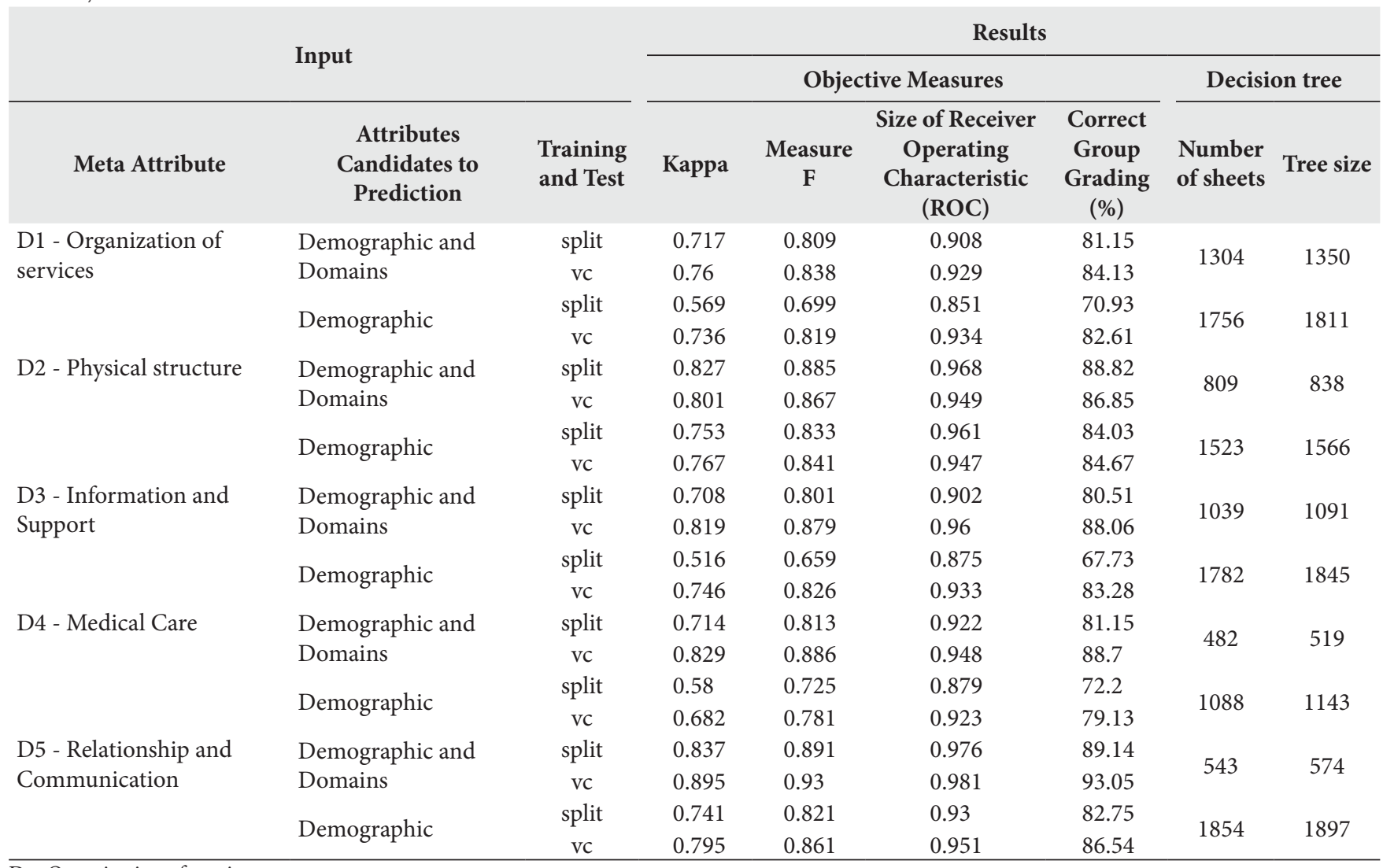

$\mathrm{D}=$ Organization of services

Table 3. Results of the J48 algoritm for the domain D5. Relation and communication from the subset of demographic attributes by the method of cross validation of 10 pairs, 2014

\begin{tabular}{|c|c|c|c|c|}
\hline \multirow{2}{*}{ Origin Group } & \multicolumn{3}{|c|}{ Classification Group } & \multirow{2}{*}{ Total } \\
\hline & low & medium & high & \\
\hline low & 218 & 6 & 36 & 260 \\
\hline medium & 0 & 332 & 0 & 332 \\
\hline high & 12 & 10 & 307 & 329 \\
\hline Measure F & 0.976 & 0.914 & 0.890 & \\
\hline ROC Size & 0.997 & 0.974 & 0.968 & \\
\hline Correct Classification of the Group & & & & $93.05 \%$ \\
\hline
\end{tabular}

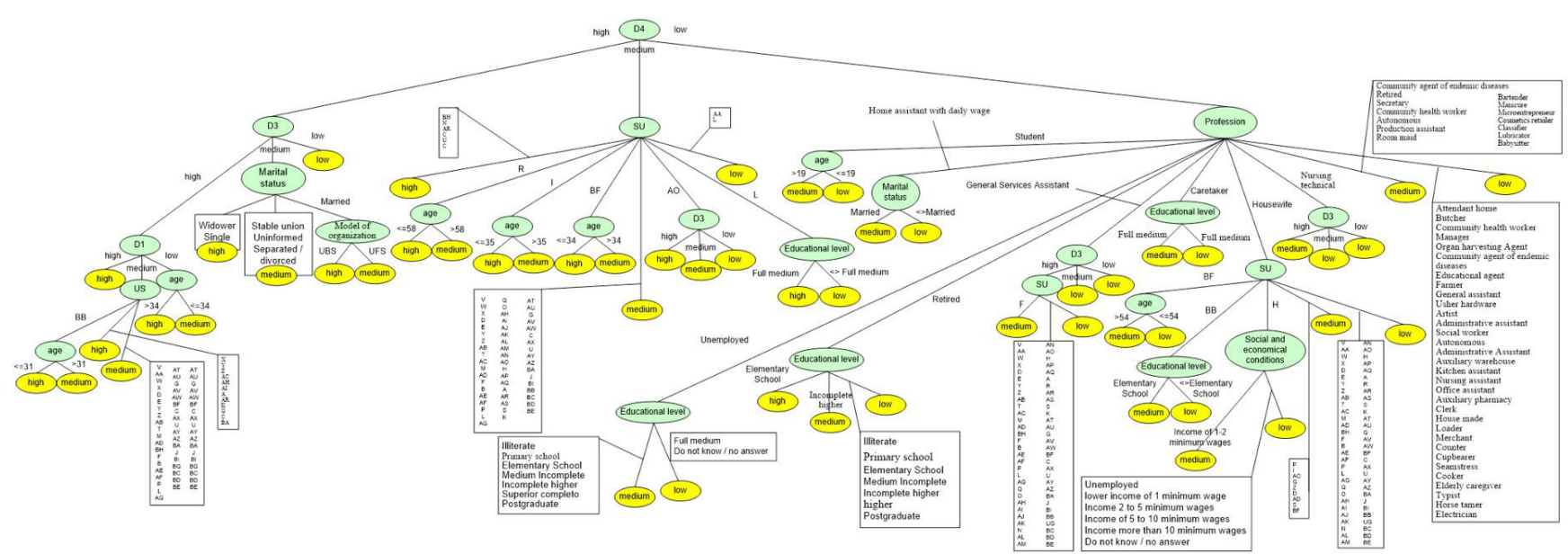

Figure 3. Decision Tree expanded to classify the domain 'Relationship and Communication', developed using the J48 classifier for cross-validation method of 10 pairs, 2014 
Table 4. Association Rules (AR1) with implication in the facet: 'time to schedule the dental appointment in the health unit', 2014

\begin{tabular}{|c|c|c|c|c|}
\hline \multicolumn{3}{|c|}{ Association Rules } & \multicolumn{2}{|c|}{ Interest Measures } \\
\hline \multicolumn{2}{|c|}{ Demographic Factor (Antecedent) } & $\begin{array}{c}\text { Satisfaction } \\
\text { (Consequent) }\end{array}$ & Lift & Conviction \\
\hline \multirow{4}{*}{$\begin{array}{l}\text { Professional } \\
\text { Ocupation }\end{array}$} & General Assistant & Low & 2.73 & 4.93 \\
\hline & Home assistant with daily wage & Low & 2.23 & 2.3 \\
\hline & Community agent of endemic & Medium & 2.31 & 2.6 \\
\hline & Production assistant & Medium & 2.24 & 2.27 \\
\hline \multirow[t]{12}{*}{ Health Unit' ${ }^{a}$} & Health Unit A & Low & 2.92 & 7.23 \\
\hline & Health Unit B & Low & 2.43 & 2.96 \\
\hline & Health Unit G & Low & 2.06 & 1.86 \\
\hline & Health Unit H & Low & 1.99 & 1.81 \\
\hline & Health Unit I & Low & 1.83 & 1.5 \\
\hline & Health Unit F & Medium & 2.02 & 1.95 \\
\hline & Health Unit K & Medium & 1.72 & 1.54 \\
\hline & Health Unit L & Medium & 1.72 & 1.54 \\
\hline & Health Unit C & High & 2.65 & 2.77 \\
\hline & Health Unit D & High & 2.47 & 2.54 \\
\hline & Health Unit E & High & 2.45 & 2.22 \\
\hline & Health Unit J & High & 2.04 & 1.59 \\
\hline
\end{tabular}

${ }^{a}$ To preserve the health units, their names were replaced by alphabetic codes

Table 5. Association Rules (AR2) with implication in the facet: 'resolvability', 2014

\begin{tabular}{|c|c|c|c|c|}
\hline \multicolumn{3}{|c|}{ Association Rules } & \multicolumn{2}{|c|}{ Interest Measures } \\
\hline \multicolumn{2}{|c|}{ Demographic Factor (Antecedent) } & $\begin{array}{c}\text { Satisfaction } \\
\text { (Consequent) }\end{array}$ & Lift & Conviction \\
\hline \multirow{3}{*}{$\begin{array}{l}\text { Professional } \\
\text { Ocupation }\end{array}$} & Home assistant with daily wage & Low & 1.87 & 1.59 \\
\hline & General Assistant & Low & 1.82 & 1.55 \\
\hline & Seller & Medium & 2.31 & 2.37 \\
\hline \multirow[t]{13}{*}{ Health Unit ${ }^{a}$} & Health Unit B & Low & 1.98 & 1.74 \\
\hline & Health Unit H & Low & 2.13 & 2.07 \\
\hline & Health Unit L & Low & 1.98 & 1.9 \\
\hline & Health Unit O & Low & 2.34 & 2.61 \\
\hline & Health Unit P & Low & 2.19 & 2.33 \\
\hline & Health Unit R & Low & 2.03 & 1.96 \\
\hline & Health Unit N & Medium & 2.31 & 2.37 \\
\hline & Health Unit Q & Medium & 2.02 & 1.94 \\
\hline & Health Unit M & Medium & 2.59 & 3.87 \\
\hline & Health Unit T & Medium & 1.76 & 1.48 \\
\hline & Health Unit U & Medium & 1.71 & 1.51 \\
\hline & Health Unit S & High & 2.32 & 1.82 \\
\hline & Health Unit E & High & 2.06 & 1.66 \\
\hline
\end{tabular}

aTo preserve the health units. their names were replaced by alphabetic codes

\section{DISCUSSION}

From DT it can be inferred that 'occupation' is one of the demographic factors most strongly related to satisfaction in all areas. This factor is still unexplored in the literature as a marker of user satisfaction with the public health service. The most frequent relations are depending on the workload and the possibility of withdrawal from labor activity for health care. Study shows that the satisfaction of users who work full time, is smaller compared to users who do not work or work part time, as well as the satisfaction is reduced of individuals with low possibility of absence from work ${ }^{7}$.

These notes may help explaining the low level of satisfaction found in this study for users with occupancy of general assistant and home assistants, both professions that have low decisional autonomy and financial provision characteristics, directly linked to the daily work practice. This result also highlights the need for public dental services in Brazil to rethink the configuration of their work process systems, emphasizing the demand for actions 
and planning services according to the working characteristics of each user, since the access of workers to health services implies the direct loss of days of work and income.

The most planning for oral health is based on epidemiological surveys and health information systems, which focus primarily on clinical conditions and records of clinical procedures ${ }^{15}$. Given the focus of the transformation, managers and health professionals should jointly consider the employment characteristics highlighted above for the implementation of a planned schedule of activities and services in health, with emphasis on the provision of alternative periods of service and appointment scheduling, also considering the night periods and weekends.

Here we highlight another important aspect of low satisfaction between general assistant and home assistants. In general, global research point unfavorable conditions of income ${ }^{7}$ and level of education ${ }^{8,11,18}$ among users as important indicators of expanding its satisfaction with the public health services. Thus, assuming that general services assistants and home assistants are often in a situation of economic and educational disadvantage, the findings of this study point to the disruption of the unrestricted association between these indicators and the satisfaction with the health network.

The 'intrinsic characteristics of each health unit' factor was found in the trees targeting the domains: 'Relationship and Communication', 'Organization of services' and 'Information and Support'. This result seems to reflect the working process of each team, the relationship between its employees and between the health team and the user, and reveal that the places that provide health services, although governed under the same model of care, are significantly heterogeneous, being its structure an important factor to Communication returning from specialists appointments' satisfaction. The findings are in accordance with the study of Liu and Chen ${ }^{9}$, which also used the data mining technique to evaluate health service. The authors found that the main segments that differ from one unit to another are management, empowerment by the health team and the reputation of the service in relation to the equipment apparatus? .

It is important to involve health teams in the effective inclusion of the findings, in the several stages that precede the actions in health, enhancing the performance of each professional for health promotion ${ }^{19}$. In this sense, it is important to emphasize the importance of training professionals working in health teams, using the innumerable protocols available in the Brazilian health care network, which allow the qualification and standardization of health processes. Despite the known benefits provided by the correct use of the protocols, it still persists underutilized at the national level. As a recent strategy to overcome this difficulty, the Brazilian Ministry of Health has been developing actions to monitor and evaluate processes and work through the National Program for Improving Access and Quality of Basic Care ${ }^{20}$.

This way, the use of Data Mining can help politicians and municipal administrators in the recognition of units providing health services regarded as satisfactory and unsatisfactory, and to identify factors that affect the quality of the health services. Thus, it becomes possible to restructure and creatively redesign internal processes of health facilities management, using as a strategy the sharing of experiences regarding the work process organization and management of human and material resources of each unit service. The inclusion of evaluation policies under consistent methodological bases and periodic trainings, could bring to professional real understanding of its importance in the process of acquiring and maintaining health of users and the motivation to infer positively throughout the system.

Factors such as age, marital status, education, socioeconomic status and gender showed low relationship satisfaction dominions. In these aspects the literature is vast and little incisive. There are studies that indicate high satisfaction with health services, associated with old age ${ }^{3,7,8,12}$, low socioeconomic status ${ }^{7}$; low level of education ${ }^{7,8,11,12}$ and masculine gender ${ }^{8}$. Other research demonstrate that the satisfaction is not influenced by demographic characteristics of the user ${ }^{18}$. The only pattern that emerges from these studies is the fact that most sociodemographic factors are weakly related to user satisfaction ${ }^{21}$.

It was also observed differences between the satisfaction level of users by municipality; however, this factor did not appear as a determinant in the classification of areas. It may have been influenced by the regional characteristics of the samples, the critical sense of more or less developed, as well as the culture of a particular place. According to the Brazilian National Commission on Social Determinants of Health ${ }^{22,23}$, differences in health perceptions can also be attributed to cultural and environmental conditions, generating a stratification of population groups.

Considering the opinion of the users about dental health services, in addition to promoting guidelines with a focus on quality, establishes the inclusion of additional dimensions to the biologist, Meeting the precepts established in the proposal of health system at national level. Allied to the fact of allowing exactness in the actions to be employed, observing the singularities of the localities ${ }^{14}$.

Finally, it reinforces that the sample characteristics found in this study do not differ from the profile of users of public health services of other similar research $3,8,10,12,15$, fact that confirms its importance and general applicability to the field of health management.

From the identification of the intrinsic characteristics of each health unit' the factor was decisive in the classification of most areas, but the limitation of analysis on the characteristics evolved in this factor, despite the foregoing assumptions, suggest 
the use of new techniques Data mining aimed at generating specific clusters.

Building studies involving the satisfaction of managers, professionals and users also becomes desirable to deepen the present findings.

In view of these findings, the proximity of the form used with the instruments commonly used to assess the public health services in Brazil, and considering the wide range of data from networks of local, regional and national health, the Data Mining was considered a safe and accurate tool to support health managers and policy makers in strategic planning and health management.

It reiterates that the use of this tool identified with greater reliability complementary factors to the user's perception of the quality of public dental health services ('occupation' and 'intrinsic characteristics of each health unit'), considering the previously disclosed markers in the literature.

\section{ABBREVIATIONS}

Alphabetic codes - Intrinsic characteristics of each health unit AR - Association Rules

$\mathrm{Cv}$ - Conviction

DT - Decision Trees

D1 - Organization of services

D2 - Physical structure

D3 - Information and Support

D4 - Medical Care

D5 - Relationship and Communication

KDD - Knowledge Discovery in Database

L - Lift

SR - Satisfaction Ratings

UBS Basic Unit Health

UNESP - Sao Paulo State University

USF Family Health Unit

\section{REFERENCES}

1. The Institute of Medicine. Crossing the quality chasm: a new health system for the 21st century. Washington: National Academies Press; 2001.

2. World Health Organization. Quality assessment and assurance in Primary Health Care: programme statement. Geneve: WHO; 1989.

3. Brandão ALRBS, Giovanella L, Campos CEA. Evaluation of primary care from the perspective of users: adaptation of the EUROPEP instrument for major Brazilian urban centers. Cien Saude Colet. 2013;18(1):103-14. http://dx.doi.org/10.1590/S1413-81232013000100012. PMid:23338501.

4. Constand MK, MacDermid JC, Dal Bello-Haas V, Law M. Scoping review of patient-centered care approaches in healthcare. BMC Health Serv Res. 2014;14(1):271. http://dx.doi.org/10.1186/1472-6963-14-271. PMid:24947822.

5. Goetz K, Campbell SM, Broge B, Brodowski M, Wensing M, Szecsenyi J. Effectiveness of a quality management program in dental care practices. BMC Oral Health. 2014;14(1):41. http://dx.doi.org/10.1186/1472-683114-41. PMid:24773764

6. Nora CR, Junges JR. Humanization policy in primary health care: a systematic review. Rev Saude Publica. 2013;47(6):1186-200. http://dx.doi. org/10.1590/S0034-89102013000901186. PMid:24626556.

7. Kontopantelis E, Roland M, Reeves D. Patient experience of access to primary care: identification of predictors in a national patient survey. BMC Fam Pract. 2010;11(1):61. http://dx.doi.org/10.1186/1471-2296-11-61. PMid:20799981.

8. Gouveia GC, Souza WV, Luna CF, Souza-Júnior PRB, Szwarcwald CL User satisfaction in the Brazilian health system: associated factors and regional differences. Rev Bras Epidemiol. 2009;12(3):281-96. http://dx.doi. org/10.1590/S1415-790X2009000300001.

9. Liu SS, Chen J. Using data mining to segment healthcare markets from patients' preference perspectives. Int J Health Care Qual Assur. 2009;22(2):117-34. http://dx.doi.org/10.1108/09526860910944610. PMid:19536963.

10. Martins AMBL, Ferreira RC, Santos-Neto PE, Carreiro DC, Souza JGS, Ferreira EF. Users' dissatisfaction with dental care: a population-based household study. Rev Saude Publica. 2015;49:1. http://dx.doi.org/10.1590/ S0034-8910.2015049005659. PMid:26270017.

11. Priporas CV, Laspa C, Kamenidou I. Patient satisfaction measurement for in-hospital services: a pilot study in Greece. J Med Mark. 2008;8(4):325-40. http://dx.doi.org/10.1057/jmm.2008.21.

12. Santiago RF, Mendes ACG, Miranda GMD, Duarte PO, Furtado BMASM, Souza WV. Quality of care in the family healthcare units in the city of Recife: user perception. Cien Saude Colet. 2013;18(1):35-44. http://dx.doi. org/10.1590/S1413-81232013000100005. PMid:23338494.

13. Fayyad U, Piatetsky-Shapiro G, Smyth P. From data mining to knowledge discovery in databases. AI Mag. 1996;17(3):37.

14. Aldosari MA, Tavares MA, Matta-Machado ATG, Abreu MHNG. Factors associated with patients' satisfaction in Brazilian dental primary health care. PLoS One. 2017;12(11):e0187993. http://dx.doi.org/10.1371/journal. pone.0187993. PMid:29145438.

15. Santos MLMF, Cruz SS, Gomes-Filho IS, Soares JSP, Figueiredo ACMG, Coelho CM. Satisfação dos usuários adultos com a atenção em saúde bucal na estratégia de saúde da família. Cad Saude Colet. 2015;23(2):163-71. http://dx.doi.org/10.1590/1414-462X201500020057.

16. Donabedian A. The quality of care: how can it be assessed? JAMA. 1988;260(12):1743-8. http://dx.doi.org/10.1001/jama.1988.03410120089033. PMid:3045356

17. Frank E, Hall MA, Witten IH. Data mining: practical machine learning tools and techniques. 4th ed. San Francisco: Morgan Kaufmann; 2016.

18. Michalski RS, Kaufman KA. Data mining and knowledge discovery: a review of issues and a multistrategy approach. In: Michalski RS, Bratko I, Kubat $\mathrm{M}$, editors. Machine learning and data mining: methods and applications. London: John Wiley \& Sons; 1998. p. 71-112.

19. Bordin D, Fadel CB, Moimaz SAS, Garbin CAS, Saliba NA. Estudo comparativo da satisfação de usuários e profissionais da saúde com o serviço 
público odontológico. Cien Saude Colet. 2017;22(1):151-60. http://dx.doi. org/10.1590/1413-81232017221.13522015.

20. Moreira KS, Vieira MA, Costa SM. Qualidade da Atenção Básica: avaliação das Equipes de Saúde da Família. Saúde Debate. 2016;40(111):117-27. http://dx.doi.org/10.1590/0103-1104201611109.

21. Ricci NA, Wanderley FS, Oliveira MS, Rebelatto JR. O hospital-escola de São Carlos: análise do funcionamento por meio da satisfação dos usuários. Cien Saude Colet. 2011;16(Suppl 1):1125-34. http://dx.doi.org/10.1590/ S1413-81232011000700044. PMid:21503460.
22. Danielsen K, Bjertnaes OA, Garratt A, Forland O, Iversen HH, Hunskaar S. The association between demographic factors, user reported experiences and user satisfaction: results from three casualty clinics in Norway. BMC Fam Pract. 2010;11(1):73. http://dx.doi.org/10.1186/1471-2296-11-73. PMid:20925930.

23. Brazilian National Commission on Social Determinants of Health. The social causes of health inequities in Brazil. Rio de Janeiro: Fiocruz; 2008.

Received on: Feb. 28, 2018

Accepted on: Dec. 13, 2018 